\title{
SÁNCHEZ RAMÍREZ, Juan Luis (2013): Las 10 mareas del cambio. Roca editorial de libros: Madrid, 128 páginas.
}

\author{
Daniel Rodrigo Cano
}

Estamos ante un cambio social apasionante, donde la gente se agrupa para reclamar los derechos que se recortan. El avance desconsiderado del neocapitalismo en manos de los mercados a los que les molestan los derechos sociales provoca desigualdades abismales. Aunque el Estado de bienestar en España no alcanzó cotas altas en comparación con los países más avanzados de Europa, los recortes que desde 2010 se han llevado en este país provocan, por un lado, el aumento de las brechas entre ricos y pobres y, por otro, la unión de los ciudadanos en las protestas, que en los últimos tiempos se han denominado "mareas". El término "marea" aglutina una fuerza colectiva de ciudadanos que dicen "basta" ante esta estafa generalizada. Las mareas son distintos movimientos, algunos de ellos desde principios de siglo, que reclaman unos derechos concretos y que en los últimos años vuelven a reivindicar desde la calle.

El autor del libro habla de 10 mareas, y como él mismo dice, sin ánimo académico, hace un recorrido por las más importantes, al menos por aquéllas que están teniendo un mayor poder de convocatoria, como las mareas por la educación o la sanidad públicas y contra los desahucios. Además, nos muestra otras que, con mucha menos presencia, son importantes tanto por su relevancia en la reclamación como en su trascendencia social, como la marea por el agua, la feminista o la de la transparencia. Como bien identifica el autor estas movilizaciones se han identificado por sus colores, así la marea de la educación es verde y es habitual hablar de la "marea blanca" como identificativo de una protesta por la sanidad. Juan Luis Sánchez va más allá y habla de las que nos muestran la necesidad de avanzar hacia el futuro como lo hacen las mareas de la tecnopolítica, la cultura libre o la constituyente. Partiendo de historias de personas, entrevistas, noticias o experiencias, el autor se adentra en las necesidades sociales que los ciudadanos reclaman en la calle frente a los atropellos que los políticos y afines comenten a diario especialmente a las 
personas más desfavorecidas. El autor deja claro que estas protestas ante unos recortes sociales están siendo seguidas por mucha más gente que los implicados socialmente, de esta forma es habitual encontrarse a padres y a sus hijos junto a docentes en la marea verde $o$ a pacientes y médicos en la marea blanca siendo copartícipes tanto los afectados directamente por los recortes como quienes lo son de forma indirecta.

Siendo un análisis periodístico, este libro es una recopilación útil para mucha gente que esté interesada en actualizar su pensamiento político con nuevas experiencias, nuevas ideas y nuevos discursos sociales ante el cambio del tejido político en España. El estilo y ritmo que imprime el autor permiten fácilmente la empatía con cada una de las personas entrevistadas, con cada historia humana que nos cuenta; todo ello envuelto de una realidad preocupante. 